\title{
THE EMPLOYMENT OF FEMALE NURSES IN THE MALE WARDS OF MENTAL HOSPITALS IN SCOTLAND.*
}

By GEORGE M. ROBERTSON, M.D., F.R.C.P.,

Physician Superintendent of the Royal Edinburgh Asylum, Morningside, and Lecturer on Mental Diseases in the University of Edinburgh.

Ten years ago I was requested by the secretary of the MedicoPsychological Association to open a discussion at the annual meeting of the Association on this subject. It was then regarded by some asylum medical officers as "the topic of the hour," largely because of certain views on administration which I had expressed and certain innovations in methods I had made at the Stirling District Asylum.

This method of caring for the insane has again come into prominence, on account of the somewhat alarming position that has been created by the shortage of male attendants in asylums. No class of the community has done its duty by voluntary enlistment for the war more loyally, and the difficulties caused by the departure of attendants, and the impossibility of getting suitable men to replace them, have been relieved in many asylums by the introduction, for the first time, of female nurses on the male side. In many other institutions the advisability of taking this departure from established routine is being seriously considered. Great interest has therefore revived in this method of care and nursing, and I have had the unusual distinction conferred upon me of being asked for the second time by the secretary of the Association to open a discussion on it. This is now a much easier task for me than it was ten years ago, for during the interval the principles and practices then advocated have been very widely adopted in Scotland. It is not too much to say that they now form a characteristic and firmly established feature of the modern Scottish system for the care of the insane.

Many of us have now grown so accustomed to female nursing, and value it so highly, that, on contemplating the subject, the question that comes most readily to our minds is-Why were women not always employed? To others who only know the mental hospital as it now is, with its carefully designed accommodation and its comfort, its good order and discipline, its skilful

* Read in London on the 17th February 1916 at the general meeting of the Medico-Psychological Association. 
and intelligent nursing staff, its prevailing atmosphere of consideration for the patients and their medical care, the question also seems a very obvious one. But the mental hospitals of to-day are not less remote from the madhouses of 125 years ago than the period we live in from the bronze age, though we are still enslaved by many archaic traditions and practices inherited from them. The madhouses at the end of the eighteenth and the beginning of the nineteenth century were not hospitals, they were prisons for the safe custody of a dangerous class. Little wonder then that the methods they adopted were those of the prison, that "keepers" alone were employed on the male side, and that women were rigidly excluded from it. The modern mental hospital can justly claim to be classed with other medical institutions, but if so, it should fall into line with them by discarding an anachronism and by making use of women's mothering instincts and natural gifts for the nursing and care of male patients as other hospitals have done. There rests, it seems to me, a heavy responsibility upon those who now fail to do so.

1. Auxiliary Female Care.-The story of the introduction of women's help on the male side of asylums forms an instructive chapter in the history of the care of the insane, but it is only possible here to refer to the most important landmarks. Judging by the inertia to their employment that still exists in many quarters, although in a neighbouring country its success is an established fact, the man who first employed women in this way must have been of a very independent and original spirit. $\mathrm{He}$ was no less a person than Dr. Samuel Hitch, the founder of the Medico-Psychological Association. He introduced this system into the Gloucester General Lunatic Asylum in the very same year that he founded the Medico-Psychological Association, namely, 1841, and could he have survived till to-day to see the development attained by the twin offspring of his mind he would have much reason to be proud of both of them. Ir. Hitch employed the wives of his married charge attendants to help their husbands in the male wards, and I was informed by his widow that it was because of the harsh manner in which the male patients were then treated by the attendants that he was induced to take this step. This statement is confirmed by the minutes of the asylum, which I was permitted to see, in which it is recorded that this woman's husband had charge of the refractory ward. Dr. Hitch's lead was followed by many English asylums during the next forty years. 
Another step in advance was taken in 1883 by Dr. R. M. Bucke of the London Asylum in Canada, who employed widows of good character in the male wards. Dr. Bucke was one of the most striking personalities of the American Medico-Psychological Association, and this experiment in his hands was a complete success.

A third step was taken by Sir Thomas Clouston, who had adopted Dr. Hitch's system, by placing a married couple in charge of the Male Hospital at Morningside. The husband then died, and in 1890 he appointed the widow in full charge, with the male attendants under her authority. He permitted her to engage the services of two ordinary asylum nurses to assist her, and occasionally female patients would help as well.

These three methods for the employment of women on the male side, namely, Dr. Hitch's, Dr. Bucke's, and Dr. Clouston's, illustrate what I regard as the phase of Auxiliary Female Care. Its defect lies in the fact that the nurses were few in number and only assisted the male attendants, and the bulk of the nursing, even in those wards in which they were employed, continued to be done by the male attendants. It would appear that no danger was apprehended to these women from the violence of the patients, but the selection of wives or widows of good character indicates that the risk of misconduct was recognised and thus guarded against.

2. Entire Female Nursing.-The first step towards the system by which a group of male patients is entirely nursed by women was taken by Dr. Turnbull in the Fife and Kinross Asylum in 1896. He placed a ward containing 30 male hospital patients, by day only, entirely under the charge of female nurses. Owing to the construction of the hospital very efficient supervision was capable of being exercised over these nurses by the Matron and the Charge Nurse of the Female Hospital. The proximity to the other male wards also enabled male help to be immediately summoned if necessary. The Scottish Commissioners in Lunacy at once realised that Dr. Turnbull's innovation constituted an important new departure and a great advance on anything that had been attempted before. Acting on the advice of Sir John Sibbald, who thought very highly of it, a similar arrangement was soon after introduced into the Glasgow (Gartloch), Lanark, and Perth District Asylums. In the year 1900, at the Stirling District Asylum, I placed a group of male patients, by night as well as by day, under the charge of female nurses, thus for the 
first time frankly handing over the entire care and nursing of insane male patients to women alone during the whole 24 hours.

These arrangements just described may very appropriately be called the S'cottish system of Entire Female Nursing, for its special features were not only developed in the Scottish asylums, but it has been very extensively adopted by them for nearly a generation. It is a totally different thing in practice from the system I have called that of Auxiliary Female Care, in which a few women assisted the male attendants. All who have had great experience of women nurses in male wards agree in saying that they are infinitely more useful if placed in sole charge of a group, and they much prefer it themselves. The patients benefit more certainly from their ministrations, for it provides a guarantee that they must be nursed by women. Under the system of Auxiliary Female Care there is a division of labour in the ward, and the nursing may be done by the men and the cleaning up and household duties by the wornen. The danger of misconduct, which has been already referred to, decreases as the number of nurses employed becomes greater, and is least when the care of a whole ward is handed over entirely to women. It must be remembered, too, that supervision and discipline in the asylums of the early and mid-Victorian period, when the system of Auxiliary Female Care was employed, were not so perfect then as they are now. What with the advent of efficient supervision and of the good class of men and women now engaged in asylum work, difficulties of this nature can be overcome and need not be feared in a modern asylum.

3. The Hospitalisation of the Asylum.-The employment of female nurses on the male side has not stopped at this stage of evolution in Scotland. Their introduction was in very large part due to the desire to make use in asylums of the very high standard of skill in nursing possessed by those who had been trained in our general hospitals. Three-quarters of a century ago, in Dr. Hitch's time, "Sarah Gamp" was in the flesh (Martin Chuzzlewit, 1843), and there cannot have been much inducement to employ her, or others like her, on the male side for the sake of their skill in nursing. Dr. Hitch's first female nurse attended to refractory patients. If this highly skilled form of nursing be desired, then women must be employed, for unfortunately men do not receive this training in our general hospitals. Large numbers of trained hospital nurses have thus been appointed during the last twelve years to the Scottish asylums in important positions for the sake of their technical skill and training. 
Dr. Campbell Clark was the first to appoint a trained hospital nurse (Miss Mary Macfarlane) to the post of matron at the Kirklands Asylum, Bothwell, in 1880. In the following year he commenced the systematic teaching and training of his asylum nurses and attendants, as was the practice in general hospitals. The idea took root, and in 1885 the Scottish Division published the Handbook for Attendants on the Insane, the most enterprising action ever taken by a Division of the Association. This handbook, as is well known, has since been adopted by the MedicoPsychological Association, and has led to the granting of the Certificate for Proficiency in Mental Nursing and to the Registration of Certificated Mental Nurses.

The first hospital nurse to work within the wards among insane patients and asylum nurses was appointed by me at the Perth District Asylum in 1896. This was an important step, not only on account of its direct influence on ward work, but because it created a supply of hospital nurses who were specially trained for the duties of asylum matronship, which had not previously existed. The demand for these became so great that over three dozen of my own nurses have received such appointments in other institutions.

As all hospital nurses are accustomed to attend to male patients in the general hospitals, they think it the most natural thing in the world to continue to take charge of male patients in asylums. They have gradually extended the sphere of their usefulness far beyond the limits of the hospital wards on the male side to which they were first appointed and have invaded other departments. They have introduced innumerable reforms which have approximated the methods employed in the asylums to those in the hospitals, and amongst these the greater employment of women in the male wards is only one. The trend of events in Scotland has been such that this employment of female nurses in the male wards, when seen in its proper perspective, is found to be only a part of a much greater scheme or ideal that has flowed like a tide over the land-that of the Hospitalisation of the Asylum. It is fifteen years now since this ideal was organised into a working system at the Stirling District Asylum, and a paper describing the methods employed there, entitled "Hospital Ideals in the Care of the Insane," was published by me in the Journal of Mental Science in the year 1902. The details of this system go, however, beyond the scope of the present paper and include the building of asylum hospitals, the bed treatment of the insane, the study of the physical aspects of mental disease, etc. 
Time is not only a great healer but a great judge, who decides most appeals by very convincing logic, and fifteen years is a liberal period in which to test the merits of a system of asylum management. It was said thirteen years ago by a distinguished member of our specialty that the "nursing of male insane patients by females" was "preposterous," and that to run everything in asylums on hospital lines was "a great fad." It must be hinted in palliation that this authority had not had any experience of the methods which he criticised so freely. This method of nursing is now as distinctive and as firmly established a feature of the Scottish system of care for the insane as the well-known BoardingOut System. It is employed in some measure or other in all but two of the important asylums of the country, and in these the superintendents have so far failed to introduce it, not because they are opposed to it on principle, but on account of structural difficulties with regard to supervision, housing, etc. This wonderful unanimity of opinion and practice amongst Scotsmen, whose national proclivities do not tend to concord, is remarkable testimony in its favour, and points to the manifest practicability and overwhelming merits of the system. The Hospitalisation of the Asylum is still, on the whole, an ideal to be aspired to, but it, too, is steadily developing and gaining ground year after year. It will perhaps come as a surprise to many to know that in a fourth of the asylums in Scotland, and among them are included some of the large ones, the matron is head of the nursing staff on the male side as well as on the female. How many hospital nurses are employed as sisters or assistant matrons it is impossible to say, but it must be large, for 22 were lately doing duty in the military hospitals. A system such as this, which has survived the test of fifteen years' experience with enhanced reputation and has become national in scope, must now have some other qualification than "preposterous," some other appellation than "a fad," applied to it by all fair-minded and reasonable men and women. The man who sees no good in it, who thinks its adoption impossible, must believe that the Scottish Board of Control and the majority of the medical superintendents in that country, in other respects men with the reputation of being shrewd and level-headed, are labouring under an obsession.

Having briefly described the history of the introduction of female nursing in the male wards of asylums, I shall now refer to certain objections and difficulties.

In the first place, it is said that this work is not a suitable form 
of employment for women. In reply to this it may be pointed out that the work in question is actually being done by women in all but two of the Scottish asylums, and the consensus of opinion in Scotland, where experience of the system is unsurpassed, not only does not support but contradicts the objection. The personal offices that all nurses, including hospital nurses, may be called upon to perform in the nursing of adult males may be objected to and have been objected to. Between fifty and sixty years ago, before the movement started by Florence Nightingale had been given time to effect a reformation, I have been informed by my teachers that no woman with any self-respect or regard for her reputation nursed adult males in our general hospitals. Women from every rank of society are prepared to do so now, and are held in the highest esteem if they do. Is it not then clear that it is not the work alone that matters, but that the spirit in which it is done, the methods that are employed, and the character of the person who comes to the work are essential elements in any judgment upon it? If, therefore, the status of hospital nursing can be so transformed in the estimation in which it is held, may not a similar change by the adoption of similar methods take place in connection with asylum nursing? If approached in the proper spirit, if performed by approved methods, and if undertaken by the right persons, this form of employment has been found in Scotland quite suitable for women.

In introducing female nurses into the male wards for the first time the most reliable women on the staff would naturally be selected by anyone who wished the experiment to be a success. They should be experienced and they should not be young. The working unit should not be less than four in number. It is a great advantage to place a hospital nurse with asylum experience in charge of them. The methods employed in handling the patients and in the management of the ward should be those which have been adopted in general hospitals, on account of their regard for the decencies. It is naturally found that these can be most readily adopted for those patients who are confined to bed. When the patients are dressed and going about it is advisable to employ auxiliary male care, in the form of one or two trustworthy married attendants, to bathe the patients and to assist in other ways if required. I have never had the least difficulty in arranging for this small amount of auxiliary male care, and I have always found convalescent and working male patients willing to help the nurses. 
In the second place, it has been said that the male side of an asylum is not a fit place for a woman to be in. The presence of good women always has a refining influence on male society, and whatever the conduct of male patients in speech and in general behaviour may be, the advent of female nurses among them, if managed with care, will effect a change for the better. The capacity of the insane for education in good habits, while not illimitable, is very extensive, and in practice it is never exhausted in our large institutions. Were we not so familiar with it, their good behaviour and self-control, for example during Divine service, would astonish us every week, as it does those who see it for the first time. If, therefore, it can be alleged of any asylum that its male wards are not a suitable place for women, then the sooner a reformation be effected the better for the patients there, for it is not a condition that need continue indefinitely.

It is then asked, are women who object to nurse male patients to be compelled to do this work? The answer is, of course not. There are women who object to nurse male patients, just as there are women who object to be nurses at all, but of the hundreds who have been nurses in the asylums of which I had charge, those who have objected during twenty years can be counted on the fingers of one hand. As a matter of fact, the vast majority prefer to do so, and the reason is not difficult to find. Male patients are always less troublesome and excitable than female, and women find that they receive more courtesy and readier obedience from men than from members of their own sex. They do not require to receive any extra salary to do this work, once it has been started, for the women are engaged, as they are in general hospitals, simply to nurse, and it is all in the day's work whether they nurse patients of the male sex or of the female. It is very doubtful if there be any saving in expenses by the employment of women instead of men, because owing to the higher standard of hospital care aspired to there is usually found to be a larger number of nurses required. In Scotland any saving there may have been from this source has been more than expended on an increased night staff, which is proportionally much larger than that employed in English asylums, and on hospital nurses for purposes of supervision, which is a practice that has now been largely adopted.

Lastly, it has been pointed out that many male patients, owing to their sexual proclivities, cannot be cared for by women. This is undoubtedly true, but the remedy is a simple one-do not place them under women; let them be cared for by men. It is 
unthinkable that any experienced administrator would allow a simple difficulty of this kind, with an obvious remedy, to deter him from the introduction of women nurses. It may give him a little more trouble, which at present he escapes, but that is no excuse for avoiding a duty. Every day of the year, in every asylum in the country, a much more difficult and responsible task of an analogous nature is faithfully performed - that of distinguishingthe patients who are suicidal from those who are not, and of making special arrangements for their care. To pick out patients whom it is undesirable to place under the care of women is, compared with this, an exceedingly simple matter.

Far from the employment of female nurses in the male wards of asylums being unsuitable in form, out of place, and objectionable to them, in the high state of organisation and development now attained by mental hospitals, whatever may have been the case in the past, it is most appropriate and a beneficent duty to the insane male patients under our care. They appear to be the last class of the helpless to benefit from the superior aptitude and skill that women show for the duties of nursing, and this privilege should no longer be denied them, as it is overdue. The reason for this superiority of female nursing rests on a solid foundationthe mothering instinct in women. It is an instinct so strong that in many cases it cannot be suppressed and must manifest itself in one form or another. There are, of course, exceptional women and exceptional men, and we have all met male attendants who have been kind and devoted nurses. Nevertheless, nursing the sick, the infirm, and the helpless, be they sane or insane, is preeminently woman's avocation. Sir Thomas Clouston summed up the situation tersely when he said that all his nurses longed to work in the hospital, whereas all his male attendants wished to be kept out of it and preferred to do outdoor work, and that he never saw a man enjoy sick-nursing in the same way as many women do.

It has been remarked that only a small proportion of the male patients are in the hospital wards, but is not a great part of the work in an asylum indoor domestic duties, which in a private house are also performed by women? The cleaning and decoration of the wards, the bed-making, the laundry and repair of the clothing, the serving of the food and the social functions are all tasks which in private life usually fall to the lot of women. Can it then be doubted that they are as efficient, if not more so, than men, to perform these familiar occupations in asylums. 
Moreover, it must not be assumed that female nurses are only of use for the care of the sick and helpless in an asylum. One of the surprises of the system in practice has been the discovery that they can usually exercise more control over cases of mania than male attendants, and the great advantage of their management lies in this fact, that it is based on persuasion and not at all on the show of force or on compulsion. Excited patients who are ready to fight any man who comes near them will often do anything they are told by a nurse, and they will become calm if they receive a word of sympathy from her. A woman has much the same influence over an insane man who is not actually delirious as she has over one who is supposed to be in his sound mind, and it is absurd to assume that all feelings of chivalry and honour die in a man because he suffers from some derangement of the mind.

The proportion of women it is desirable to employ on the male side of an asylum is, according to the Scottish Board of Control, at least 25 per cent. of the total day staff on the male side and 15 per cent. of the night staff: These figures are considerably exceeded in several asylums, among which may be mentioned the Stirling District Asylum. It may be taken as a typical county asylum in the accommodation it provides, in its complete organisation, and in the modern methods it employs. It admits over 250 patients annually, and has a resident population of over 800 . Dr. R. B. Campbell, its medical superintendent, has employed for the last $7 \frac{1}{2}$ years, as I also did for an equal period, a staff on the male side by day of which 40 per cent. consist of women, there being 3 hospital nurses, including the matron. By night 27 per cent. of the staff consists of women, including the night superintendent, who is a trained hospital nurse.

It has been stated that female nurses are more suitable for asylums admitting parochial than private patients of the richer classes. That has not been my experience at Craig House. This is the department of the Royal Edinburgh Asylum for private patients, and it is quite a separate mental hospital from the West House, which provides accommodation for poorer patients. Of the staff of 32 employed on the male side by day to attend to 100 gentlemen, exactly one-half consists of nurses, including in this number the lady superintendent and 3 matrons, and of these 3 are hospital nurses. By night 6 out of a staff of 13 consist of women, including the night superintendent, who is a trained hospital nurse. These proportions vary from day to day according to requirements, and they have perhaps been swelled by the war, 
but there is no difficulty in employing 40 per cent. of women by day and 25 per cent. by night in a private asylum like Craig House. Of course there are special difficulties connected with private male patients which are not met with in the case of parochial patients, but the employment of women in their care on the whole is equally advantageous. The opinion of the friends of patients is worth quoting. The most interested relatives of gentlemen consist chiefly of anxious females, be they mothers, wives, or sisters, and nothing in my experience gives them greater comfort than to know that the relatives whom they entrust to our care will be tended by women. Rightly or wrongly, to them it is a guarantee that no violence will be employed, and that the most skilled nursing will be available.

In conclusion I have to state that these opinions-whatever may be their value-are founded on twenty years' experience of entire female nursing in male wards, and have been gained in four different asylums of which I have had charge during that time. I am now more convinced than ever that the mental hospital-the modern asylum-is only a hospital for the treatment of a special disease, and therefore requires to be run on hospital lines, of which the employment of women in the male wards is only one feature. Although many did not see eye, to eye with me in the past I have learned to be patient, and I have had the satisfaction of seeing these views gradually accepted and the methods I advocated adopted. The ultimate hospitalisation of the asylum is now only a question of time, and that time has been hastened by the action of many medical superintendents of the English asylums, who, owing to one of the results of the war, have introduced female nursing in the male wards of their asylums for the first time. I trust that the observations I have made may assist others in coming to a similar decision. 